\title{
Cuidados Paliativos Oncológicos - Controle de Sintomas*
}

\author{
Cancer palliative care in oncology symptom control
}

\section{INTRODUÇÃO}

0 otimismo sobre 0 controle das doenças não parece ser fiel, visto o crescente de doenças crônicas que temos vivenciado, talvez em muito devido ao envelhecimento da população.

Cientes de nossa limitação como profissionais da saúde, devemos deixar de pensar a finitude ou a doença crônica como um fracasso da medicina, visto ser 0 alívio da dor e do sofrimento uma das metas da medicina.

A finitude digna pode ser definida como aquela sem dor e com sofrimento minimizado mediante os cuidados paliativos adequados, onde cabe equilibrar as necessidades do paciente e a integridade médica.

N esta habilidade pressuposta da medicina estão inclusos os cuidados paliativos. Cuidados totais prestados ao paciente e à sua família, os quais se iniciam quando a terapêutica específica curativa deixa de ser 0 objetivo.

A terapêutica paliativa évoltada ao controle sintomático e preservação da qualidade de vida para o paciente, sem função curativa, de prolongamento ou deabreviação da sobrevida.

A empatia, bom humor e compreensão são integrantes fundamentais da terapêutica. A abordagem é multidisciplinar, contando com médicos, enfermeiros, psicólogos, assistentes sociais, nutricionistas, fisioterapeutas e voluntários.

Certamente o fracasso na remissão de sintomas ocorrem, em muitas vezes, pela não abordagem do paciente como um todo, envolvido em seu contexto social.

Acompanhamos a evolução clínica através da escala de capacidade funcional perfomance status (Tabela 1), o que nos permite definir as condutas a seguir relacionadas.

\section{ESCALA DE CAPACIDADE FUNCIONAL}

Tabela 1. Performance status (PS)

\begin{tabular}{l|l}
\hline \multicolumn{1}{c|}{ Escala de Zubrod (ECOG) } & \multicolumn{1}{c}{ Escala de Karnofsky (\%) } \\
\hline PS 0 - Atividade normal & $\begin{array}{l}100 \text { - nenhuma queixa: ausência de } \\
\text { evidência da doença }\end{array}$ \\
\cline { 2 - 2 } & $\begin{array}{l}90 \text { - capaz de levar vida normal; sinais } \\
\text { menores ou sintoma da doença }\end{array}$ \\
\hline $\begin{array}{l}\text { PS 1 - Sintomas da doença, mas deambula } \\
\text { e leva seu dia a dia normal }\end{array}$ & $\begin{array}{l}80 \text { - alguns sinais ou sintomas da doença } \\
\text { com o esforço }\end{array}$ \\
\cline { 2 - 2 } $\begin{array}{l}70 \text { - capaz de cuidar de si mesmo; incapaz } \\
\text { de levar suas atividades normais ou exercer } \\
\text { trabalho ativo }\end{array}$ \\
\hline PS 2 - Fora do leito mais de 50\% do tempo & $\begin{array}{l}60 \text { - necessita de assistência ocasional, } \\
\text { mas ainda é capaz de prover a maioria } \\
\text { de suas atividades }\end{array}$ \\
\cline { 2 - 2 } $\begin{array}{l}50 \text { - requer assistência considerável e } \\
\text { cuidados médicos freqüentes }\end{array}$ \\
\hline PS 3 - No leito mais de 50\% do tempo, carente & $\begin{array}{l}40 \text { - incapaz; requer cuidados especiais e } \\
\text { assistência }\end{array}$ \\
\cline { 2 - 2 } de cuidados mais intensivos & $\begin{array}{l}30 \text { - muito incapaz; indicada hospitalização, } \\
\text { apesar da morte não ser iminente }\end{array}$ \\
\hline PS 4 - Preso ao leito & $\begin{array}{l}20 \text { - muito debilitado; hospitalização necessária; } \\
\text { necessitando de tratamento de apoio ativo }\end{array}$ \\
\cline { 2 - 2 } & $\begin{array}{l}10 \text { - moribundo, processos letais progredindo } \\
\text { rapidamente }\end{array}$ \\
\hline
\end{tabular}

O bs.: otimizar e revisar sempre a medicação prescrita. Avaliar o benefício almejado.

\section{PRINCIPAIS SINTOMAS E MEDIDAS TERAPÊUTICAS}

\section{AgITAÇão PSiCOMOTORA / CONFUSÃO MENTAL}

Estado confusional resultante da queda da função mental em curto espaço de tempo. Pode ser caracterizado por distúrbio da consciência, alteração da cognição ou ter etiologia orgânica.

- Evitar opiáceos;

- O bservar corticoterapia (Tabela 2). 0 corticóide geralmente favorece uma sensação de bem estar, porém pode causar insônia, psicose, agitação e depressão. $\mathrm{N}$ ão tem estes efeitos dependentes da dose, porém é mais comum quando o uso é crônico e em dose alta, tendo ocorrido alteração abrupta da dosagem;

\footnotetext{
* Esta é uma edição atualizada e ampliada do Controle de sintomas e cuidados paliativos de criança: condutas do IN CA. Publicada na Revista Brasileira de Cancerologia 2000;v.46,n.2,p.137-45; e do Controle de sintomas do câncer avançado em adulto: normas e recomendações do IN CA/M S. Publicada na Revista Brasileira de Cancerologia 2000;v.46,n.3,p.243-56,
} coordenada pela Doutora Claudia Burlá. 
- Buscar causas desencadeantes, geralmente multifatorial:

- hemorragia, metástase cerebral, interação de medicamentos, infecção, alterações metabólicas e nutricionais (hipoglicemia, hipercalcemia, hipocalemia, hiponatremia), impactação fecal, retenção urinária, hipoxemia, dor, hospitalização, doença eidade avançadas.

\section{Conduta:}

- Corrigir alterações desencadeantes na medida do possível;

- Avaliar e suspender drogas possíveis e reduzir as que não podem ser suspensas. Se em uso de opióide, promover rodízio do mesmo; se com suspensão abrupta do corticóide, retornar à dose prévia;

- Proceder orientação do paciente e cuidador e tranqüilizar 0 ambiente. Prevenir acidentes.

\section{Medicacóes:}

- haldol - casos leves: 1mg 3x dia VO;

- casos severos - 2,5 a 5mg SC ou IM ou 1 a $10 \mathrm{mg}$;

- diluídos em 10mI ABD IV até $3 x$ dia;

- clorpromazina 25 a 75mg/dia;

- midazolam até $30 \mathrm{mg} /$ dia (infusão EV ou SC em casos graves);

- dexametasona - 16 a 36mg /dia V O (se com metástase cerebral).

\section{CORTICÓIDE / EFEITOS ADVERSOS}

- N europsiquiátricos: alucinações, paranóia, delírio, depressão e ansiedade;

- Úlcera péptica: o risco aumenta na associação com anta inflamatórios não hormonais;

- M iopatia: uso crônico pode levar a miopatia proximal, especialmente nas pernas. Eventualmente podem afetar a musculatura respiratória;

- H iperglicemia: 0 aumento da glicemia se dá por aumentar a resistência à insulina e por afetar o transporte muscular de glicose não insulino dependente. Paciente com diabetes induzido por uso de corticóides aumentam muito o risco de desenvolver comorbidades, como infeções, e agravar seu estado com um quadro severo de hiperglicemia. 0 acompanhamento regular de pacientes de risco deve reduzir as complicações por hiperglicemia. Além do controle específico para diabetes, uma hidratação adequada deve ser observada de forma criteriosa;

- D or: o corticóide aumenta a osteoporose. Sua contribuição para o aumento da do óssea metastática é incerta, mas sabe-se que podem induzir a necrose asséptica da cabeça do fêmur, além de mialgias a artralgias quando da redução da dosagem;

- Q ueimação perineal: só ocorre quando fazemos infusão rápida de dexametasona, em dose de 20 a 100 mg. Este sintoma é de caráter transitório;

- Pseudoreumatismo: síndrome álgica que afeta músculos e articulações, associada a redução rápida ou lenta de corticóides, após períodos longos ou curtos de tratamento. Seu tratamento consiste em retornar a dose mais elevada do que estava sendo usada, seguido de uma lenta retirada;

- Pacientes de risco: os que recebem o equivalente a $20 \mathrm{mg} / \mathrm{dia}$ ou menos de prednisolona tem baixo risco de desenvolver as complicações descritas. A miopatia ocorre mais freqüentemente com 0 uso da dexametasona, betametasona e triamcinolona. Assim, pacientes que necessitam de tratamento a longo prazo devemos dar preferência a prednisolona, reduzindo a dose o mais breve possível. 0 uso em dias alternos também reduz a incidência de efeitos adversos.

Tabela 2. Equivalência de doses

\begin{tabular}{l|l|l|l}
\hline Cortisona & $25 \mathrm{mg}$ & Triancinolona & $4 \mathrm{mg}$ \\
\hline Hidrocortisona & $20 \mathrm{mg}$ & Fluocortolona & $5 \mathrm{mg}$ \\
\hline Prednisona & $5 \mathrm{mg}$ & Metilenoprednisolona & $6 \mathrm{mg}$ \\
\hline Prednisolona & $5 \mathrm{mg}$ & Parametasona & $2 \mathrm{mg}$ \\
\hline Metilprednisolona & $4 \mathrm{mg}$ & Betametasona & $0,75 \mathrm{mg}$ \\
\hline Dexametasona & $0,75 \mathrm{mg}$ & & \\
\hline
\end{tabular}

\section{ALTERAÇÕES DA MUCOSA ORAL}

Comum após radio e quimioterapia. Acarreta perda da ingestão oral, aumenta doença periodontal, causa desconforto social e predispõe a infeções.

O corre devido a debilidade orgânica, diminuição da ingesta oral, uso de drogas, ansiedade, respiração oral e tumoração local.

\section{Conduta:}

\section{- Aumentar ingesta hídrica;}


- M anter a boca sempre úmida;

- H igiene bucal com escovação de dentes e língua. U sar colutório freqüentes;

- Evitar alimentos ácidos;

- Evitar jejum prolongado;

- Controle da dor.

\section{Medicações:}

- Úlcera infectada - metronidazol 250mg 8/ $8 \mathrm{~h}$ VO mucosite - nistatina 5 a $10 \mathrm{ml}$ com $5 \mathrm{ml}$ de lidocaína gel em $10 \mathrm{ml}$ deágua (diluir, bochechar e engolir $4 \mathrm{x}$ dia);

- Candidíase - nistatina 3 conta-gotas 4 a $5 x$ dia VT ou fluconazol 150 mg dose única $V 0$;

- H erpes Zoster e Simples - acyclovir 200 mg

5 x dia por 5 dias; estomatite aftosa corticóide tópico.

\section{DESCONFORTO BUCAL NA CRIANÇA}

Candidíase bucal, úlceras aftosas, herpes e outras infecções acometem a criança submetida a tratamento oncológico, e sob cuidados paliativos na fase avançada da doença, provocando desconforto bucal.

\section{Tratamento:}

- H igiene bucal com solução bicarbonatada a $1 \%$;

- Solução de xilocaína viscosa a 2\% diluída em água. $\mathrm{N}$ ão ultrapassar $3 \mathrm{mg} / \mathrm{K} \mathrm{g} /$ dose e não repetir antes de 2 horas;

- Morfina em infusão endovenosa contínua pode ser utilizada em caso de dor forte,em dose baixa;

- M orfina $0,03 \mathrm{mg} / \mathrm{Kg} / \mathrm{h}$ - IV.

\section{AGRESSIVIDADE NA CRIANÇA}

Pode ser de intensidade variada e muitas vezes é decorrente de alterações metabólicas e neurodegenerativas. $D$ eve-se atentar para 0 risco de auto-agressão e de agressão a terceiros, e também para o impacto que causa aos familiares.

\section{Conduta:}

- Suporte emocional para a criança e seus familiares e cuidadores;

- H aloperidol 0,25mg duas vezes ao dia, podendo aumentar até $5 \mathrm{mg}$;

- Prometazina para prevenir os efeitos colaterais decorrentes do uso do haloperidol
- 0,5mg/K g/dose IM ou IV em 30 minutos ou a cada 8-12 horas VO.

\section{ANOREXIA}

Perda do apetite é o $2^{\circ}$ sintoma mais comum em pacientes com câncer avançado, presente em $65 \%$ - $85 \%$ dos casos.

Estudos demonstram que 0 apetite e a habilidade de comer são mais importantes do que a força física e habilidade de trabalhar. (Padilla, 1986).

Apetite e ingesta alimentar são fatores importantes na qualidade de vida para 0 paciente.

- D escartar candidíase oral, dor, impactação fecal, náuseas, uso de fármacos e hipercalcemia.

\section{Conduta:}

- Permitir a ingestão em pequenas quantidades e a intervalos regulares de alimentos de seu agrado. Incentivar as refeições junto à família.

\section{Medicacão:}

- dexametasona $6 \mathrm{mg} / \mathrm{dia}$ ou prednisona 5 a $15 \mathrm{mg} /$ dia - ação por curto prazo (cerca de 1 mês);

- metoclopramida $10 \mathrm{mg} \mathrm{VO}$ antes das refeições (favorece o esvaziamento gástrico) megestrol 160mg/dia.

Anorexia é normal nos últimos dias de vida e é necessário que a família do paciente aceite essa limitação.

\section{ORIENTAÇÃO DE ALIMENTAÇÃO DA CRIANÇA}

A alimentação é orientada após avaliação do estado nutricional e das condições clínicas do paciente. Com o objetivo de evitar broncoaspiração, deve ser oferecida posicionando-se o paciente em 30 graus, com o pescoço flexionado para frente. Em casos de distúrbios da deglutição, pode ser utilizada sonda naso-enteral, sendo a gastrostomia outra opção para casos selecionados.

Em pacientes terminais, a alimentação está indicada para todos que tenham fome e algum grau de consciência. Pacientes comatosos, em geral, não requerem alimentação. Entretanto, mesmo sabendo que a criança não sente fome ou do real perigo de pneumonite por aspiração, os pais ou 
responsáveis podem querer alimentar a criança, o que deve ser considerado e discutido.

A anorexia pode derivar de desconforto bucal, náuseas, dificuldade de deglutir, constipação, dor, doença avançada, depressão, uso de fármacos ou disfunção neurológica irreversível. Se possível, deve-se tratar a causa.

- Aconselhar aos pais oferecer à criança pequenas quantidades dos alimentos preferidos, independentemente dos valores nutricionais.

- M etoclopramida 0,1a 0,2mg/Kg, pode ser utilizada em alguns casos, antes das refeições para melhorar a motilidade gástrica. D ose máxima de 0,8mg/Kg/24 horas.

\section{ASCITE}

Efusão líquida ou quilosa na cavidade peritoneal. Acarreta desconforto abdominal, aumento do volume abdominal, ortopnéia, náuseas e vômitos.

Consideramos ascite pequena /média a que necessita drenagem a cada 15 dias ou mais; e ascite volumosa: é a que necessita drenagem com intervalo menor do que 15 dias.

\section{Conduta:}

- Paracentese - é o método de retirar líquido da cavidade abdominal;

- No procedimento deve-se evitar aderências, órgãos parenquimatosos ou massas, alças intestinais distendidas e bexiga.

- Indicações - ascite com desconforto abdominal ou respiratório;

- Contra-indicações - distensão importante de alças; diátese hemorrágica; parede abdominal com celulite ou furunculose; falta de colaboração do paciente.

O bs.: explicar o procedimento ao paciente e ao familiar.

- Pessoal e material:

profissional de saúde treinado;

equipo de soro e coletor de drenagem;

cateter venoso tipo jelco 14 ou 12;

solução anti-séptica (álcool a 70\%);

gazes estéreis;

luva estéril; xilocaína a 1 ou $2 \%$ sem adrenalina; agulha 40x 12; 25x 8 e 13x 4,5;

seringa de $10 \mathrm{ml}$;

esparadrapo;

gorro e máscara.

- Técnica:

paciente em decúbito dorsal;

local de punção mais seguro: quadrante

inferior esquerdo;

preparar a pele com anti-séptico;

usar luvas estéreis;

anestesiar a pele e os tecidos mais

profundos;

aplicar o cateter perpendicularmente a

parede abdominal, percebendo

a passagem para cavidade peritoneal; retirar a agulha mantendo fixo o cateter; conectar o cateter ao equipo e este ao coletor (que deve ser fixado abaixo do nível de punção);

após drenagem desejada, retirar o cateter e proceder ao curativo.

O bs: descrever no prontuário o volume e 0 aspecto do líquido retirado.

- Terapêutica: clínica sugerida pelo serviço. Ascite pequena/média: é a que necessita drenagem a cada 15 dias ou mais. Avaliação quinzenal;

Ascite volumosa: é a que necessita drenagem com intervalo a menor que 15 dias. Avaliação semanal.

Aos interval os determinados:

1a etapa: espironolactona $200 \mathrm{mg}+$ furosemida $40 \mathrm{mg}$

2a etapa: espironolactona $400 \mathrm{mg}+$ furosemida $80 \mathrm{mg}$

O bs.: observar o aumento da ingesta ou reposição de cloreto de potássio.

\section{CONSTIPAÇÃO INTESTINAL}

Evacuação em intervalo menor que 3 dias, ou menos freqüente que 0 habitual para 0 paciente.

Este sintoma muito comum, debilitante está presente em aproximadamente $40 \%$ dos casos de câncer avançado, sendo prevalente 
em $90 \%$ dos pacientes usando opióide.

Fatores de risco: imobilidade, baixa ingesta hídrica, dieta com pouca fibra, hipocalemia, hipercalcemia, uso de opiáceos, uso de antidepressivos tricíclicos, uso de hioscina, uso de clorpromazina.

Pode ser causado por compressão tumoral do intestino ou invasão do plexo.

D esconforto familiar e falta de privacidade também podem ser agentes causadores.

U sualmente pode ser identificado por queixa de anorexia, náuseas, vômitos, dor abdominal, diarréia paradoxal e incontinência urinária, tenesmo, obstrução intestinal delírio em idosos.

\section{Conduta:}

- Prevenir sempre;

- O rientação nutricional;

- Proceder ao toque retal, pal pação e ausculta abdominal. D esimpactação e retirada digital de fecaloma se necessário;

- H idratação.

\section{Medicação:}

- laxativos - priorizar quando em uso de opióides;

- óleo mineral 20 a 40ml 1 a 3x dia;

- supositório de glicerina 2/2 dias . principalmente em pacientes paraplégicos;

- clister glicerinado - quando as medidas anteriores não surtirem o efeito desejado ou como medida inicial para esvaziamento do cólon.

\section{CONSTIPAÇÃO INTESTINAL NA CRIANÇA}

Imobilidade, disfunção muscular, síndormes pseudo-obstrutivas, estenose anal adquirida, distúrbios metabólicos e medicamentos podem causar constipação intestinal.

Considerar se há distúrbio metabólico reversível; caso não haja, estão indicados lubrificantes e laxativos.

- Ó leo mineral - deve-se ter cuidados especiais com pacientes neurológicos pelo risco de borncoaspiração. N estes casos pode-se usar supositórios ou enemas.

\section{Dose de ataque:}

5 a 11 anos $=30 \mathrm{ml}$ para cada $10 \mathrm{Kg}$, dividido em 2 a 4 vezes ao dia.

12 a 15 anos $=45 \mathrm{ml} /$ dia dividido em 1 a $3 x$ ao dia.

- D eve ser sempre utilizado para pacientes em uso de opiáceos: 5-10ml/dose - VO 1-4 vezes ao dia;

- Aumento da ingestão de fibras na dieta e aumento da ingestão de líquidos;

- Fibras, supositórios e enemas: são contraindicados em pacientes neutropênicos e plaquetopênicos.

Causas neuro-muscularesnão melhoram com laxativos osmóticos (óleo mineral) e estes ainda aumentam a incontinência fecal. $N$ estes casos, usar mais fibras na dieta e supositórios para estimular a defecação. Casos individualizados, em pacientes não neutropênicos e não plaquetopênicos, após discussão com a equipe, pode ser utilizada a estimulação por enema.

\section{CONVULSÃO}

Causas mais comuns: tumor, acidente vascular encefálico, doença pré existente.

Causas menos comuns: hipóxia, metabólica (uremia, hipoglicemia, hiponatremia, sepse), uso de drogas ou álcool.

M etástase cerebral não seu tratamento profilático (exceto quanto o primário é mela noma).

Tratamento deve ser iniciado quanto e se ocorrer crise convulsiva.

\section{Medicação:}

- fenitoína $100 \mathrm{mg} 3 \mathrm{x}$ dia $\mathrm{V} 0$;

- carbamazepina 100 a 200mg 2x dia Vo convulsão focal;

- dexametasona 16 a 24mg/dia VO se com hipertensão intracraniana.

Quando grave, em coma profundo a medicação é suspensa. Se com sobrevida de dias, havendo necessidade, usar fenobarbital 100 a $200 \mathrm{mg}$ IM / dia ou 200 a $300 \mathrm{mg} / \mathrm{dia}$ $\mathrm{SC}$.

\section{CONVULSÃO NA CRIANÇA}

O corre por progressão de doença neurológica ou alteração metabólica. 


\section{Conduta:}

- D iazepam - 0,2mg/Kg/dose, até 3 doses.

Seguido de: fenitoína;

D ose de ataque: $15 \mathrm{mg} / \mathrm{Kg} /$ dose

D ose de manutenção: 5 a $7 \mathrm{mg} / \mathrm{Kg} / \mathrm{dia}$

dividido em 2-3 doses.

- Caso não cessem, associar:

- Fenobarbital

D ose de ataque: $10-20 \mathrm{mg} / \mathrm{Kg} /$ dose

Dose de manutenção: $3-5 \mathrm{mg} / \mathrm{Kg} / \mathrm{dia}$

dividido em 1-2 doses.

- Caso a criança já faça uso prévio de um dos anticonvulsivantes:

- Carbamazepina

D ose de ataque: $10 \mathrm{mg} / \mathrm{Kg} /$ dose via retal, nasogástrica ou nasoduodenal

D ose de manutenção: $10-40 \mathrm{mg} / \mathrm{Kg} / \mathrm{dia}$

dividida em $8 / 8$ ou $6 / 6$ hora.

\section{DEPRESSÃO}

Sintoma muito comum em pacientes com câncer. Pode mimetizar outras doenças.

D eve ser tratado mesmo em fase avançada da doença se houver perspectiva de melhora da qualidade de vida do paciente.

Fatores de risco: câncer avançado; dor; história prévia de depressão ou alcoolismo; uso de corticóides, bloqueadores $\mathrm{H} 2$, benzodiazepínico, neurolépticos, levodopa, desordens endócrinas, doenças neurológicas como AVE eParkinson; deficiência nutricional (folato, B12).

D os critérios de avaliação de depressão, os somáticos (anorexia, perda de peso, fadiga, insônia, constipação e perda da libido) são menos importantes no câncer avançado, quando priorizamos os sintomas psicológicos:

- sensação de perda;

- sentimento de culpa;

- diminuição do prazer;

- pensamento suicida.

\section{Conduta:}

- Abordagem médica e psicológica ao paciente e família.

\section{Medicação:}

- *tricíclicos (podem causar boca seca, constipação intestinal, retenção urinária, hipotensão postural, sedação, taquicardia, dentre outros)

- amitriptilina 75 a 150mg / dia em 3 tomadas
- como tem efeito sedativo, a maior fração da dosagem deve ser feita à noite

- imipramina 25 a 150mg / dia em 3 tomadas

- bons resultados na incontinência urinária

* inibidores da recaptação de serotonina

(menos efeitos colaterais);

sertralina 25 a $200 \mathrm{mg} / \mathrm{dia}$;

citalopram 20 a 60mg/dia.

As drogas antidepressivas tem efeito iniciado a partir da $2^{\circ}$ semana de uso e os efeitos colaterais precedem os terapêuticos.

O bs.: evitar com anorexia, cefaléia, náusea e insônia (usar preferencialmente).

\section{DEPRESSÃO NA CRIANÇA}

A observação de seu comportamento e de suas reações é particularmente importante. Q uando a psicoterapia não for suficiente, deve-se usar medicação antidepressiva.

\section{Conduta:}

- Suporte emocional à criança e a seus familiares e cuidadores;

- Amitriptilina ou Imipramina - iniciar com $10 \mathrm{mg} /$ dia, aumentando para $20 \mathrm{mg} /$ dia para crianças entre 5 e 8 anos; para até 50mg para crianças de 9 a 14 anos; e para maiores até $75 \mathrm{mg} / \mathrm{dia}$;

- Citalopram - 20mg/dia somente para pacientes acima de 15 anos. Provoca menos efeitos colaterais.

\section{DERRAME PLEURAL}

Volume anormal de líquido na cavidade pleural.

A toracocentese é o método de aspiração de líquido pleural, através de uma agulha ou cateter, introduzido através da pele e parede torácica.

Indicação terapêutica: alterações da função respiratória devido ao derrame pleural volumoso, com conseqüente colapso pulmonar e disfunção respiratória.

C ontra indicações: diátese hemorrágica incorrigível ou terapêutica anticoagulante.

Avaliação e preparo do paciente: obter exame radiológico do tórax póstero anterior, perfil e decúbito lateral (Laurel) quando possível. 
O bs.: explicar o procedimento ao paciente e familiar.

- Pessoal e material:

Profissional de saúde treinado;

Equipo de soro, cateter 14 ou 18, solução anti-séptica, gazes estéreis, luvas estéreis, xilocaína a $1 \%$ ou a $2 \%$ sem adrenalina, agulhas $n-25$ ou 23 , seringas de 5 e $10 \mathrm{ml}$, esparadrapo, gorro e máscara.

- Técnica:

Colocar o paciente sentado, com as costas retas e os braços apoiados em uma mesa a sua frente, no encosto de sua cadeira ou nos joelhos;

Localizar o derrame através de exame físico e identificar a margem superior da macicez;

D everá ser introduzida a agulha a dois espaços intercostais abaixo da margem superior da macicez na região posterolateral do tórax. Guiar sempre a agulha sobre a borda superior da costela inferior. 0 ponto escolhido para punção deve ser marcado por pressão com a unha ou outro objeto que marque a pele sem ser removido pelo anti-séptico;

Luvas estéreis;

Preparar a pele com anti-séptico;

Anestesiar a pele e os tecidos mais profundos no local desejado e marcado anteriormente até a pleura parietal (aspirar a seringa antes de cada injeção, para certificarse de que 0 anestésico não está sendo injetado diretamente em um vaso;

Se alcançar o periósteo da costela, anestesiá-lo. Em seguida dirigir a agulha para cima da costela, avançando-a, aspirando e anestesiando o trajeto, até que ocorra refluxo de líquido pleural para dentro da seringa. Se não conseguir obter líquido pleural, tentar fazer com que o paciente se incline para trás em direção à agulha;

Retirar a agulha e aplicar o cateter na mesma direção e profundidade da agulha até a saída do líquido pleural;

Conectar o equipo a extremidade do cateter;

Abrir o equipo e abaixar para um depósito coletor;

Após retirar o líquido desejado, retirar o cateter e fazer um curativo, tomando cuidado de manter o cateter com seu orifício tampado para evitar a formação de pneumotórax.

\section{Cuidados no procedimento:}

- D renagem lenta;

- Deve-se interromper ou diminuir a drenagem temporariamente quando apresentar tosse ou desconforto, devido ao risco de desenvolvimento de um quadro de edema agudo de pulmão após uma rápida expansão do parênquima pulmonar;

- Percutir e auscultar hemitórax, verificando se existe pneumotórax;

- O bter um exame radiológico do tórax, expirado póstero anterior, para verificar se existe pneumotórax (se possível).

\section{Complicações:}

- Pneumotórax: por entrada de ar externo pelo cateter ou lesão do parênquima pulmonar pela agulha;

- H emotórax por lesão de artéria intercostal;

- H ipoxemia, ocorre após toracocentese, mais pode ser evitado pela administração temporária de oxigênio.

A pleurodese é um procedimento cirúrgico no qual se introduz no espaço pleural substâncias irritantes químicas, que levam a forte aderência entre as pleuras viscerais (pulmão) e parietais (superfície interna da cavidade torácica).

\section{Indicações:}

PS até 3;

Efusão pleural que reacumule rapidamente ou repetidamente após três toracocenteses;

Expectativa de vida $>1$ mês;

Derrame pleural livre (não septado) e periférico (decorrente da inflamação da superfície pleural com aumento da permeabilidade capilar e transudação de líquido no espaço pleural).

- Técnica (profissional de saúde médico): Paciente em decúbito dorsal ou lateral;

Assepsia e anti-sepsia. Anestesia local com lidocaína a 2\% sem adrenalina;

Colocação de dreno de tórax (28 ou 32 F), em linha axilar média, no 60 ou 70 espaço intercostal, em selo d'água (pressão negativa 
de 15 a $20 \mathrm{~cm} \mathrm{H}^{2} \mathrm{O}$ );

Permanecer drenado por 2 a 3 dias, buscando o contato entre a superfície pleural parietal e visceral e com drenagem $<200 \mathrm{ml} /$ 24 horas;

RX de tórax para certificar de que todo 0 líquido foi evacuado;

Analgesia central;

- Instilação de solução esclerosante através do dreno de tórax:

Tetraciclina $2 \mathrm{~g}$ diluído em $80 \mathrm{ml}$ de solução salina $+20 \mathrm{ml}$ lidocaína $1 \%$ sem adrenalina.

D eixar dreno fechado por 6 horas;

M obilizar o paciente a cada 2 horas para "distribuir" o agente esclerosante;

Abrir o clampe do dreno após as 6 horas e deixá-lo em selo d'água ( $15 \mathrm{~cm} \mathrm{H}^{2} 0$ ) por 48 horas;

Retirar o tubo.

\section{Complicacões:}

A não re-expansão completa do pulmão é uma complicação que pode dificultar futuras tentativas de pleurodese devido a aderência irregular provocada, o que permite a formação de um novo derrame pleural desta vez possivelmente septado;

A infecção da cavidade pode propiciar a formação de um empiema pleural e até 0 encarceramento pulmonar, o que provoca 0 agravamento do quadro clínico do doente;

A dor é um sintoma comum, mas é de fácil controle com o uso de opiáceos nos pós operatório imediato.

\section{DiaRRÉIA}

Evacuação líquida de 3 ou mais episódios ao dia. 0 corre em $5 \%$ a $10 \%$ dos pacientes com câncer avançado.

Excluir a falsa diarréia causada por fecaloma, obstrução intestinal parcial, intolerância alimentar, cólon irritável, ansiedade ou medo.

\section{Conduta:}

- Se pós gastrectomia, orientar ingestão de pequenos volumes de alimento.

- Excluir uso de: antiinflamatório não hormonal, diuréticos, antiácido com magnésio, beta-bloqueadoras, laxativos, reposição de ferro e antibioticoterapia.
- D escartar concomitância de D iabetes mellitus, colite ulcerativa ou doença de C rohn. - Rever dieta inadequada ou alimentação através de cateter nasoentérico ou gastrostomia, presença de tumor no intestino, fístula gastrocólica ou enterorretal, insuficiência do sistema nervoso autônomo; - H idratação, seja pelo tubo gastrointestinal, venosa ou subcutânea. Avaliar necessidade de repor potássio;

- Se após radioterapia, indicado uso de antiinflamatório não hormonal;

- Síndrome carcinóide - indicado bloqueador H 2 - 150 a $300 \mathrm{mg} / \mathrm{dia}$;

- Alça cega com crescimento bacterianometronidazol 1,5g/dia por 2 a 4 semanas;

- Sangramento tumoral por lesão baixa (reto)

- acido épsilon aminocapróico 100 a 200mg/ kg 3 a 4x dia;

- Se infecciosa - tratar causa base.

\section{DiaRRÉIA NA CRIANÇA}

Pode ocorrer por alteração da reabsorção de líquidos, por alteração da mucosa intestinal (desnutrição), hipersecreção de líquidos para a luz do intestino, por endotoxina bacteriana, secreção de peptídeo intestinal vasoativo (em casos de neuroblastoma), hipermotilidade ou hiperosmolaridade do inestino (laxativos). Pode também ocorrer por infecção patológica da flora intestinal normal e infecções oportunísticas, como por Cryptosporydium el sospora beli. 0 utros agentes causadores de diarréia são os protozoários Giárdia lamblia e Entamoeba histolytica, bactérias como a Salmonela, vírus como os Rotavírus e Citamegalovírus e fungos, particularmente a Candida albicans.

- M anter a alimentação com dieta branda. - Evitar alimentos ácidos, gordurosos e condimentados.

\section{Conduta:}

- Tratar a causa, sempre que possível;

- Suspender laxativos e rever a medicação.

Terapia de reidratação oral (TRO):

Pode prevenir e tratar alguns casos de desidratação.

- Solução de reidratação oral: fórmula da O M S/U N ICEF, produzida pelo M inistério da Saúde (M S). 
Diarréias sem sinais de desidratação:

- Ensinar parentes e cuidadores a reconhecer sinais de desidratação: boca seca, pouca urina, muita sede;

- Aumento da ingestão de líquidos;

- O ferecer TRO após cada evacuação:

$<12$ meses - 50 a $100 \mathrm{ml}$;

$>12$ meses - 100 a $200 \mathrm{ml}$.

\section{Diarréias com sinais de}

desidratação:

- Instituir TRO - 50 a 100ml/Kg no período de 4 a 6 horas;

- Com vômitos reduzir o volume administrado e aumentar a freqüência de administração;

- Com dificuldade de ingerir o soro, vômitos persistentes ou distensão abdominal: reposição venosa conforme necessidades individuais.

\section{DISPNÉIA}

O grau da dispnéia pode não estar diretamente relacionado a severidade do quadro clínico, visto ser um sintoma subjetivo.

Avaliar sempre a causa base.

O corre em aproximadamente 60 a $70 \%$ dos pacientes com câncer avançado.

\section{Conduta:}

- Na dispnéia do câncer avançado é preconizado o uso de nebulização com morfina;

- Usar morfina 2,5mg associado a dexametasona $2 \mathrm{mg}$ (a dose da morfina pode ser aumentada até $50 \mathrm{mg}$ ) diluído em 2,5ml de SF $0,9 \%$ para evitar o causado pela ABD; - Associar fenoterol se houver ausculta com broncoespasmo não aliviado pelo corticóide; - Q uando sem resposta à morfina tentar nebulização com furosemida $20 \mathrm{mg}$.

- M anter a cabeceira el evada, preferencialmente 0 paciente sentado e 0 ambiente bem ventilado;

- Se com hipoxemia, indicar oxigenioterapia: - A indicação é definida pela coleta de amostra de sangue arterial, com o paciente em ar ambiente, para a realização de gasometria;

- critério único para indicação da necessidade de oxigenioterapia foi definido como o hipóxia em ar ambiente com PaO 2 < 85mm g;

- A administração de 02 é feita sob cateter naso faringe.

\section{Condições associadas à indicação e suas conseqüências:}

- Associada ao diagnóstico de hipóxia por gasometria arterial, são adotados os seguintes critérios clínicos:

Lesões pulmonares múltiplas ou extensas, primárias ou secundárias aqui incluída linfangite carcinomatosa.

O bstrução de vias aéreas extrínsecas ou intrínsecas.

\section{Contra-indicações:}

Anemia, asma, doença pulmonar obstrutiva crônica, corpo estranho, infeções, insuficiência cardíaca congestiva, entre outras causas agudas que possam acarretar hipoxemia, deverão ser tratadas primariamente a causa base.

\section{Coleta de sangue para gasometria arterial:}

- Puncionar preferencialmente da artéria radial e manter comprimido pós punção por 10 minutos;

- U sar sempre luva de procedimento;

- Colher em seringa de $5 \mathrm{ml}$ descartável previamente heparinizada;

- Vedar a agulha com rolha de borracha;

- M anter refrigerado em caixa de isopor com gelo - separar a seringa do contato direto do gelo;

- Entregar direto no laboratório.

Descartar possibilidade de embolia pulmonar, quando é indicado heparinização plena $(1000 \mathrm{U} / \mathrm{h})$ e controlar o Tempo de Coagulação em 2 a $3 x$ o normal. Proteger mucosa gástrica.

- Se obstrutiva, desobstruir vias aéreas superiores e avaliar necessidade e indicação de traqueostomia (critério de PS até 3 e avaliação clínica);

- Checar possibilidade de síndrome de veia cava superior - é recomendado o uso de dexametasona $24 \mathrm{mg}$ IV + 8 a $12 \mathrm{mg} /$ dia ou prednisona $1 \mathrm{mg} / \mathrm{kg} / \mathrm{dia}$ - avaliar RXT (vide protocolo anexo);

- Soluço - indicado uso de clorpromazina 25 
mg 4/4h VO ou $12,5 \mathrm{mg} \mathrm{IV} 4 / 4$ horas ou $6 /$ 6 horas; metoclopramida $10 \mathrm{mg} 8 / 8$ horas; midazolam 2 a $10 \mathrm{mg}$ IV/dia;

- Broncoespasmo - aminofilina $6 \mathrm{mg} / \mathrm{kg}$ em $200 \mathrm{ml}$ de SG $5 \%$ em 30 minutos + manutenção 0,25 a 0,75mg/kg/h;

Associar hidrocortisona 300 a $500 \mathrm{mg}$ IV.

Após crise aminofilina $100 \mathrm{mg} 3 \mathrm{X}$ dia V 0 .

- Checar necessidade de punção aliviadora para ascite ou derrame pleural - vide capítulo; - Insuficiência cardíaca congestiva - indicado o uso de furosemida 20 a $80 \mathrm{mg}$ IV ou VO + inibidor da enzima de conversão da angiotensina em dose baixa (6,25 a $12 \mathrm{mg} 2 \mathrm{x}$ dia);

- Tosse - indicado codeína suspensão aquosa 30 a $60 \mathrm{mg} / \mathrm{dia}$ - manter por cerca de 1 semana após remissão de sintomas. $N$ ão associar morfina;

Associar broncodilatador e manter paciente hidratado (avaliação dínica).

- Afastar possibilidade insuficiência cardíaca congestiva e efeito colateral do inibidor da enzima de conversão da angiotensina.

- Excesso de secreção brônquica - indicado mucolítico 3 a 4 x dia e nebulização com salina com ou sem fenoterol;

- Rever se há anemia severa - indicado hemotranfísuãa se $\mathrm{H} b<7$ e com sangramento controlável;

- Ansiedade crônica - indicado uso de benzodiazepínico $5 \mathrm{mg}$ IV ou $10 \mathrm{mg} \mathrm{V} 0$;

- Dor;

- O bstrução tumoral:

- Rever RXT;

- D exametasona 8 a 12mg - evoluindo para $4 \mathrm{mg} /$ dia pela manhã após melhora dos sintomas.

- Linfangite - dexametasona 4 a 12mg/dia.

Rever associação com diurético devido a retenção fluida. Considerar uso de opióides e ansiolíticos;

- Dispnéia persistente - iniciar morfina 5 a 10mg 4/4 horas;

- Pneumonia - vide protocolo de uso de antibióticos.

\section{DISPNÉIA NA CRIANÇA}

Sintomas de insuficiência respiratória incluem irritabilidade, medo de dormir, sonolência diurna, cefaléia matutina, palpitações e náuseas. $\mathrm{Na}$ angústia da dificuldade respiratória é muito importante a confiança na equipe terapêutica

\section{Pode-se utilizar:}

- O xigênio;

- Cabeceira elevada;

- O piáceos (morfina);

- Benzodiazepínicos:

M idazolan - 0,1-1mcg/Kg/hora.

Associada à morfina quando houver taquipnéia, com fáceis de sofrimento e uso dos músculos acessórios da respiração.

- Punção aliviadora ou drenagem pleural fechada e pleurodese em caso de derrame pleural;

- Transfusão de concentrado de hemácias em caso de anemia;

- Punção aliviadora ou paracentese em caso de distensão abdominal por ascite;

- Dimeticona VO e sonda de alívio, em caso de deglutição de ar e estase gástrica;

- Radioterapia paliativa em caso de síndrome de compressão medular de veia cava superior;

- Traqueostomia em caso de obstrução de vias aéreas superiores por tumor.

\section{DISTÚRBIO DO SONO}

É comum a inversão do ciclo sono-vigília. A insônia ocorre em $29 \%$ a $59 \%$ dos pacientes com câncer avançado.

Rever causa base (dor, náusea, dispnéia, medo ou ansiedade, medicação - corticóide, teofilina, diuréticos, propranolol e metildopa, sedação diurna uso de álcool, cafeína e cigarro).

\section{Conduta:}

- Tentar eliminar causas desencadeantes;

- Promover tranqüilidade no ambiente.

\section{Medicações:}

- Benzodiazepínico 10mg;

- Associar opióide noturno se com dor; - Associar antidepressivo se com dor (amitriptilina 25mg $2 \mathrm{~h}$ antes de deitar); - $\mathrm{H}$ aldol 0,5 a $2 \mathrm{mg}$ a noite se com delírio.

O bs.: se usar corticóide ou diurético, fazer dose única pela manhã. 


\section{DISTÚRBIO DO SONO NA CRIANÇA}

Este tipo de distúrbio pode ter causas variadas, como depressão, alterações metabólicas ou uso de alguns medicamentos. A insônia pode causar ansiedade e irritabilidade na criança, e muitas vezes também desestabilizar o familiar ou cuidador uma vez que seu sono fica comprometido.

\section{Conduta:}

- Suporte emocional à criança e aos familiares cuidadores;

- Benzodiazepínico - 0,12- 0,8/K g/24h dividido em 6/6 horas ou 8/8 horas.

\section{ANSIEDADE NA CRIANÇA}

Pode ser manifetada pela criança de diversas formas como inquietude, irritabilidade, agitação e angústia, sendo que essa é muitas vezes verbalizada pela criança. É necessário que a criança esteja acompanhada por alguém que seja afetivamente significativo para ela eque sintase acolhida pela equipe. 0 uso de corticóides por períodos prolongados pode causar sintomas psicóticos, que geralmente vêm acompanhados de intensa ansiedade. Q uando necessário pode ser introduzida medicação anti-ansiolítica.

\section{Conduta:}

- Suporte emocional à criança e a seus familiares cuidadores;

- Benzodiazepínico: 0,12 - 0,8/K g/24h dividido em $6 / 6$ ou $8 / 8$ horas;

- H aloperidol: $0,01-0,1 \mathrm{mg} / \mathrm{Kg} /$ dose a cada 8-12 horas $\mathrm{VO}$. Somente em casos de sintomas psicóticos como delírio e alucinações;

- Prometazina para prevenir efeitos colaterais decorrentes do uso de haloperidol $-0,5 \mathrm{mg} /$ $\mathrm{Kg} /$ dose - IM ou IV em 30 minutos ou a cada 8-12 horas VO.

\section{FADIGA}

É a sensação de cansaço extremo devido a combinação de sintomas físicos e mentais. Praticamente universal nos estágios finais da doença.

Fatores desencadeantes: pós quimio e radioterapia, uso de corticóides, distúrbios metabólicos (por exemplo: hipoglicemia, hipopotassemia, hipercalcemia, insuficiência hepática ou renal, distúrbios tireoidianos), sangramento, sedação, sepse, depressão, deficiência nutricional, medicamentos, dentre outros.

\section{Conduta:}

- Embora fadiga seja o sintoma mais comum em pacientes com câncer avançado, é 0 sintoma para o qual temos as soluções menos satisfatórias;

- Identificar e reverter, se possível, a causa base;

- Q uando a fadiga ainda é leve, estimular pequenas atividades físicas para preservar força muscular;

- Ajudar o paciente a estabelecer prioridades.

\section{Fratura patológica}

0 corre mais comumente em câncer de mama (53\%), de rim (11\%), pulmão (8\%) e tireóide $(5 \%)$.

Comum em região cervical, fêmur e úmero.

0 paciente apresenta dor, deformidade no membro acometido com, por vezes, equimose.

O s objetivos são: aliviar a dor, preservar mobilidade quanto possível e facilitar 0 cuidado ao paciente.

\section{Conduta:}

- Analgesia apropriada;

- Fixação interna e radioterapia paliativa.

$\mathrm{Na}$ impossibilidade de outra conduta, prover calha gessada anti rotatória na fratura de fêmur ou tipóia canadense para dar maior conforto ao paciente.

- Bi fosfonatos podem reduzir eventos no esqueleto, sendo indicado para progressão das metástases ósseas e fraturas patológicas, (dose $=60$ a 90mg diluídos em $500 \mathrm{ml}$ de solução salina, infundida em 4 - 12 horas).

\section{HIPERTENSÃO ARTERIAL SISTÊMICA}

Avaliada por níveis tensóricos não ocasionais acima de $150 \times 90 \mathrm{mmH} \mathrm{g}$.

Sintoma pouco freqüente.

Avaliar presença de ansiedade, dor ou qualquer desconforto do paciente, quando é 
necessário minimizar a causa base.

\section{Medicação:}

- hidroclorotiazida 25 a $50 \mathrm{mg} / \mathrm{dia} ;$

- bloqueador - propranolol 80 a 240 mg /dia;

- atenolol 50 a 100 mg/dia;

- evitar no broncoespasmo, ICC, bloqueio átrio ventricular, bradicardia, sangramento, diabetes mellitus;

- IECA - captopril 25 a 50 mg 2 a 3xdia;

- pode ocorrer rash cutâneo, tosse irritativa, angioedema, proteinúria, leucopenia;

- bloqueador do canal de cálcio - nifedipina

10 a 30 mg 3 a $4 x$ dia;

- não associar a bloqueadores. Pode causar edema de M M II.

\section{HIPERTENSÃO INTRACRANIANA NA CRIANÇA}

$O$ corre em pacientes terminais com tumores de sistema nervoso central.

\section{Conduta:}

- D exametasona

dose de ataque: $1 \mathrm{mg} / \mathrm{Kg} /$ dose $\mathrm{VO}$ ou IV; dose de manutenção: $1 \mathrm{mg} / \mathrm{Kg} / 24 \mathrm{~h}$ dividida em $4 / 4$ ou $6 / 6$ horas.

- M anitol

$0,25 \mathrm{~g} / \mathrm{Kg} /$ dose IV em 20-30 minutos e, se preciso, aumentar até $1 \mathrm{~g} / \mathrm{Kg} /$ dose.

- Furosemida

$1 \mathrm{mg} / \mathrm{Kg}$ junto ou 5 minutos antes do manitol.

- Em caso de hidorcefalia

- Acetazolamida - 25 mg/Kg/dia V0, dividido em e doses. M áximo de $100 \mathrm{mg} / \mathrm{Kg} / \mathrm{dia}$. U so individualizado.

- Em caso de cefaléia intensa em pacientes não terminais, enquanto se aguarda 0 efeito das medidas antihipertensivas, opta-se pela analgesia com cloridrato de tramadol para evitar alteração do sensório.

\section{ESPASTICIDADE NA CRIANÇA}

Pode estar associada a tumores do sistema nervoso central.

\section{Conduta:}

- Diazepam

0,12 a $0,8 \mathrm{mg} / \mathrm{Kg} / \mathrm{dia}$, dividido em $6 / 6$ ou $8 / 8$ horas, Vo; dose sedativa e miorelaxante.

- Baclofeno
10 a 15 mg/dia a cada 8 horas; dose máxima: uso individualizado;

2 a 7 anos $=40 \mathrm{mg} / \mathrm{dia}$; maiores de 8 anos $=60 \mathrm{mg} / \mathrm{dia}$.

- Clonidina: uso individualizado. dose inicial de $0,05 \mathrm{mg} /$ dose à noite e aumentar para $0,05 \mathrm{mg}$ em 24 horas, com intervalo de 1 semana; dose máxima de 0,3 a 0,4 mg/dia. Retirada gradual em 4 dias.

\section{HIPERCALCEMIA}

É a emergência metabólica mais comum em oncologia ocorrendo em $10 \%$ a $20 \%$ de todas as neoplasias.

D efinido pelo cálcio sérico corrigido > $11 \mathrm{mg} / \mathrm{dl}$.

Sinais e sintomas: desidratação, anorexia, fadiga, dor, prurido, apatia, irritabilidade, hiporreflexia, dentre outros.

M ais freqüente: mieloma múltiplo, câncer brônquico, metáteses ósseas, câncer de mama, tumor de células escamosas de cabeça e pescoço e câncer de tireóide.

Imobilidade, uso de diuréticos tiazídicos e desidratação podem contribuir para esta ocorrência.

\section{Conduta:}

- H idratação - 2 a 3 ISF 0,9\%/24 horas respeitando a avaliação clínica do paciente pode ser suficiente para pacientes assintomáticos com cálcio sérico corrigido em até $12 \mathrm{mg} / \mathrm{dl}$;

- Repor potássio se necessário;

- Pamidroato - iniciar após hidratação e adequado débito urinário (se cálcio corrigido $>12 \mathrm{mg} / \mathrm{dl}$ ) 15 a $90 \mathrm{mg}$ IV em $500 \mathrm{ml}$ SF 0,9\% por 4 horas - efeito em 4 a 5 dias.

Acetamin ofen $500 \mathrm{mg}$ para prevenir febreapós infusão do pamidroato.

cál cio corrigido = cálcio $\mathrm{mg} / \mathrm{dl}+0,8$ (4al bumina sérica)

\begin{tabular}{l|c}
\hline & DOSE RECOMENDADA \\
\hline Cálcio sérico até $13 \mathrm{mg} / \mathrm{dl}$ & 15 a $30 \mathrm{mg}$ \\
\hline 13 a $15 \mathrm{mg} / \mathrm{dl}$ & 30 a $60 \mathrm{mg}$ \\
\hline$>15 \mathrm{mg} / \mathrm{dl}$ & 60 a $90 \mathrm{mg}$ \\
\hline
\end{tabular}


$\mathrm{N}$ a hipercalcemia crônica: incentivar deambulação, se possível aumentar a ingesta hídrica; evitar diuréticos tiazídicos, bloqueador $\mathrm{H} 2$ e preparações que contenham cálcio; corticóide - prednisona 20 a $40 \mathrm{mg} /$ dia se diagnóstico de mieloma ou linfoma; clodronato $1600 \mathrm{mg} / \mathrm{dia}$.

\section{HIPERGLICEMIA}

A intolerância à glicose é uma das primeiras anormalidades metabólicas descritas em pacientes com câncer avançado. 0 corre antes mesmo da perda de peso e da caquexia. Com a progressão do câncer, piora a resistência periférica à insulina, determinando dificuldades no controle glicêmico.

\section{Conduta:}

- D uas ou mais dosagens da glicemia de jejum $>110 \mathrm{mg} / \mathrm{dl}$;

- O bservar corticoterapia crônica;

- O rientar dieta;

- H ipoglicemiante oral - clorpropamida 125 a $1000 \mathrm{mg} /$ dia dividido em até 3 tomadas (observar menor concentração da divisão da dose na possibilidade de hipoglicemia noturna);

- Insulina NPH - indicada se não houver controle com hipoglicemiante oral.

O bs.: após titulação da dose de insulina regular de acordo com a glicemia capilar pré prandial $4 \mathrm{x}$ dia.

Aplicar insulina regular SC de acordo com o intervalo de variação da glicemia capilar (atenção aos diferentes valores orientados pelas diversas marcas de fita).

Em geral:

até $180 \mathrm{mg} \%$ não fazer;

81 a $240 \mathrm{mg} \% 2$ a 4 UI;

241 a $300 \mathrm{mg} \% 3$ a $6 \mathrm{UI}$;

301 a 400mg \% 4 a 8UI;

acima de $400 \mathrm{mg} \% 6$ a $10 \mathrm{UI}$.

Cálculo de N PH : somar o total de unidades usadas de insulina regular/dia administrada em 3 dias consecutivos e dividir por 3. Do quarto ao sexto dias aplicar $1 / 3$ a $1 / 2$ da dose da insulina N PH calculada antes do desjejum e manter o mesmo esquema de controle com a insulina regular.
Ao término do sexto dia, somar as unidades de insulina regular necessárias nesta segunda etapa, dividir por 3 e acrescentar $1 / 3$ a 1/2 das unidades calculadas de insulina N PH ao primeiro cálculo.

\section{LINFEDEMA}

A ocorrência nos M M SS está em $40 \%$ dos casos relacionada a linfadenectomia axilar e RXT; nos M M II geralmente decorre de tumoração pélvica.

$\mathrm{Na}$ indisponibilidade de realizar color doppler e outros complementares, devemos excluir tumoração, cisto, ascite, trombose venosa profunda, insuficiência cardíaca congestiva e baixa acentuada da dosagem sérica de albumina.

\section{Conduta:}

- O bservar se há queixa do paciente;

- O bservando a função renal, aumentar, se possível, a ingesta protéica;

- Antibióticos (critérios já estabelecidos) devemos dar ênfase em prevenir (por ex. com uso de penicilina $V$ - 0,5 a $1 \mathrm{~g}$ a cada 6 ou 8 h). Para tratamento usamos por 14 dias conforme sensibilidade apresentada.

- D renagem postural:

Compressão - visa manter diminuído o vol ume do membro;

Suporte - quando a diminuição do membro não é prevista ou é desnecessária;

Exercício - visando preservar o movimento do membro acometido;

Se linfedema de M M II - compressão, se

M M SS - compressão e suporte;

$\mathrm{H}$ igiene - sugerimos uso de permanganato de potássio.

- U so de diurético: furosemida 40 a 80mg/ dia associado a espironolactona 200 a 400mg/ dia no caso de edema generalizado;

- Se sem sucesso após 2 a 3 dias o uso de diuréticos, iniciar dexametasona $16 \mathrm{mg} /$ dia (caso de compressão linfática);

- Q uando com comprometimento venoso associado (tumor ou trombose), acrescentar corticóide ao diurético. U sar anticoagulante (cumarínico ou Acido acetil salicilico). $\mathrm{N}$ ão esquecer do bloqueador $\mathrm{H}^{2}$;

- Infiltração tumoral - suporte;

- Pele frágil - suporte e compressão;

- Linforréia - rever perda da continuidade. 
Fazer compressão por cerca de 48h (aplicando vaselina). Prevenir infecção;

- Por tumor abdominal ou pélvico - usar corticóide (dexametasona $16 \mathrm{mg}$ ) e diurético (furosemida 40 a $80 \mathrm{mg}+$ aldactone $200 \mathrm{e}$ $400 \mathrm{mg}$ ).

\section{NÁUSEA E VÔMITOS}

0 correm em $60 \%$ dos pacientes com câncer avançado.

Particularmente prevalecente em tumor de mama, estômago ou tumores ginecológicos.

Sessenta por cento dos pacientes recebendo opióides, especialmente no início da terapêutica apresentam esses sintomas que desaparecem em poucos dias.

Q uando possível reverter a causa base (fármacos, constipação ou obstrução intestinal, alteração metabólica, tosse, uremia, molinhasse oral, quimio e radioterapia, medo ou ansiedade, dentre outras).

\section{Conduta:}

- Aconselhamento nutricional.

\section{Medicacão:}

- 1 - metoclopramida 10 a 20mg 3 a 4x dia IV ou SC - acelerar o esvaziamento gástrico;

- 20 haldol 0,5 a 2mg 4x dia IM ou 5 a 15 $\mathrm{mg} / \mathrm{dia} \mathrm{SC}$ - casos com uremia e hipercalcemia;

- 3o prometazina 25mg 2 a 3x dia - ação central e de receptores colinérgicos periféricos; - 4ㅇ dexametasona $4 \mathrm{mg} / \mathrm{dia}$. C aso com hipertensão intracraniana - 16 a $36 \mathrm{mg} / \mathrm{dia}$; - 50 ondansetron 8mg IV ou VO 2 a $3 x$ dia principalmente após radioterapia.

O bs.: plenitude pós prandial - bromoprida 20 a $60 \mathrm{mg} / \mathrm{dia}$;

Rever: necessidade de CNG (se + de 2 episódios de vômitos a cada 6 horas);

GTO descompressiva- o procedimento tem como critérios: PS até 3, avaliação clínica e ausência de insuficiência renal).

NÁUSEA E VÔMITOS NA CRIANÇA

A causa deve ser determinada e tratada. - O ferecer alimentos em quantidade reduzida e em menor intervalo.

- Evitar alimentosde odor forte, salgados,ácidos, gordurosos e condimentados.

\section{Tratamento:}

- M etoclopramida - 0,1 a 0,2mg/K g/dose -IV ou IM ou Vo de $8 / 8$ horas;

- O ndansetrona - $5 \mathrm{mg} / \mathrm{m} 2 /$ dose - IV ou VO a cada 8 horas. É altamente ativo para o tratamento da náusea e do vômito induzido por QT, mas experiências sugerem ser menos efetivo para estes sintomas, quando não devidos à quimioterapia;

- D exametasona:

dose inicial: 10mg m2/dose - IV (máximo de $20 \mathrm{mg}$ );

doses subsequentes: $5 \mathrm{mg} / \mathrm{m} 2 /$ dose - IV de 6/6 horas.

- Prometazina - 0,25 a 0,5 mg/K g/dose - IV ou $\mathrm{VO}$ a cada 4- 6 horas;

- $\mathrm{H}$ aloperidol - 0,01 a 0,1 mg/K $/$ /dose -VO a cada 8-12 horas.

Obstrução intestinal

Situação na qual o trânsito através do trato gastro intestinal é retardado ou obstruído.

- M aior causa é carcinomatose peritoneal mais freqüente no tumor de ovário - $40 \%$, seguida de tu de cólon e retal - $20 \%$, e pâncreas, estômago e colo de útero;

- $30 \%$ dos pacientes tem patologia obstrutiva benigna;

Sintomas:

- vômitos;

- dor;

- distensão abdominal;

- peristalse aumentada;

- parada de eliminação de gases e fezes.

Exame físico: inclui toque vaginal e retal, rotina de abdome agudo e exames laboratoriais (rever distúrbios metabólicos, a ex.: potássio e cálcio).

\section{Conduta:}

- D iferenciar entre abdome agudo clínico e cirúrgico.

Clínico:

- D ieta zero;

- CNG em sifonagem se ocorrerem mais de 3 episódios em 6 horas (avaliar a vontade do paciente);

- HV (40 a $50 \mathrm{ml} / \mathrm{kg} / \mathrm{dia})$ + reposição 
eletrolítica;

- O bservar indicação do haloperidol 0,5mg

$3 x$ dia, como tratamento sintomático.

Cirúrgico:

- PS até 3 (correção de prolapso - PS até 2);

- M etástase hepática, ascite ou insuficiência

renal contra-indicam 0 procedimento cirúrgico;

- Dieta zero;

- CN G - conforme já descrito;

- H V - conforme já descrito;

- Anti-espasmódico - hioscina até 240mg / dia IV;

- Bloqueador $\mathrm{H}^{2}$ - ranitidina 50mg IV 8/8 horas;

- M etoclopramida- 1 ampola IV até $6 / 6$ horas;

- Transfusão de hemáceas se necessário manter $\mathrm{H} \mathrm{b}>7 \mathrm{mg} \%$;

- D emais sintomáticos.

0 bs.: PS até 3, sem indicação de colostômia, rever benefício de GTO descompressiva (considerar se com uso permanente do CNG após 2 semanas).

Tabela 3. Obstrução intestinal maligna - (não cirúrgica)

\begin{tabular}{l|c}
\hline \multicolumn{1}{c|}{ INDICAÇ̃̃ES } & DOSE SC OU IV \\
\hline Metoclopramida & $10 \mathrm{mg}-6 / 6 \mathrm{~h}$ \\
\hline Brometo de N. Butil Escopolamina & $20 \mathrm{mg}$ até $4 / 4 \mathrm{~h}$ \\
\hline Haloperidol & $5 \mathrm{mg}-2 \mathrm{x}$ dia \\
\hline Octreotide & 150 a $300 \mathrm{mg}$ /infusão contínua \\
\hline
\end{tabular}

\section{OBSTRUÇÕES MECÂNICAS PARCIAIS NA CRIANÇA}

C ausadas por tumores e aderências ou, por refluxo gastrintestinal. Freqüente em pacientes neuropatas.

\section{Tratamento:}

- Metoclopramida para aumentar 0 esvaziamento gástrico, 0,1 a $0,2 \mathrm{mg} / \mathrm{Kg} /$ dose - (IV ou IM ou VO) de 8/8 horas;

- H idróxido de alumínio com magnésio - 5$15 \mathrm{ml} V 0$ a cada 3 - 6 horas;

- Ranitidina 1 - 2mg/Kg/dia, dividido em 3 doses IV ou 2 - 4mg/Kg/dia dividido em 2 doses VO.

\section{SANGRAMENTO}

Excluir trauma, coagulopatia, fármacos, insuficiência hepática grave, coagulação in- travascular disseminada, plaquetopenia etc.

\section{Conduta:}

- Sedação se necessário com benzodiazepínico 5 a 20 mg IV ou - midazolam 5 mg IM ou IV.

\section{Medicação:}

- reposição com SF 0,9\%;

- TGI - suspender AINH e corticóide. Caso de vômito, iniciar antiemético:

- usar ranitidina 300mg 12/12 horas;

- considerar uso de acido épsilon

aminocaproico.

- transvaginal - avaliar uso tampão vaginal;

- iniciar acido épsilon aminocapróico 100 a

$200 \mathrm{mg} / \mathrm{kg} 3$ a $4 \mathrm{x}$ dia (IV diluir em 250 a

$500 \mathrm{ml}$ de SF $0,9 \%$ ou SG $5 \%$ );

- hemoptise severa - ácido épsilon aminocapróico (dose descrita acima);

- hemoptise discreta - iniciar codeína;

- epistaxe - tamponamento nasal anterior e gelo local;

- sangramento oral - soro gelado;

- considerar acido épsilon aminocapróico;

- sangramento do estoma - compressão local;

- transretal - avaliar uso de acido épsilon aminocapróico 100 a 200mg/kg 3 a 4x dia (IV diluir em 250 a $500 \mathrm{ml}$ de SF $0,9 \%$ ou SG 5\%);

- hematúria - irrigação com cateter de triplo lúmen;

- Compressão local e curativo compressivo;

- RXT - vide protocolo;

- Ligadura de carótida externa - procedimento de urgência realizado em pacientes que possam se beneficiar. Evitar lesão cervico oral extensa e congelamento cervical;

- Em cuidados paliativos, entendemos que 0 procedimento de transfusão deva ser avaliado com critério, tendo definido quando 0 paciente estiver severamente sintomático, podendo se beneficiar do procedimento.

Anemia e astenia são sintomas comuns em pacientes com câncer avançado.

É questionada a relação entre a diminuição dos níveis de $\mathrm{Hb}$ e a fadiga.

\section{Hemotransfusão:}

- dispnéia: pacientes alertas $\mathrm{Hb}<7,0$ mg \%;

- sangramento TGI, TGU, CP: sintomas severos decorrentes da perda sangüínea, 
quando esta pode ser controlada.

0 bs.: 0 ácido épsilon aminocapróico é um poderoso inibidor da fibrinólise. Trombos formados durante seu uso não sofrem lise.

Vitamina K tem seu uso ligado a tendência de sangramento associada à sua deficiência (alimentar, má absorção, obstrução do trato biliar intra ou extra - hepático, uso de drogas). D ose 10 a $20 \mathrm{mg}, \mathrm{IM}$, obtendo resposta em cerca de 24 horas.

\section{SANGRAMENTO NA CRIANÇA}

Constitui situação estressante para a criança e para a família.

\section{Conduta:}

Em caso de sangramentos externos

- Transfusão de concentrado de plaquetas - se há trombocitopenia;

- Transfusão de concentrado de hemácias em caso de anemia aguda;

- Ácido épsilon-aminocapróico - em caso de sangramento de mucosa bucal;

- Vitamina K e plasma fresco - em caso de insuficiência hepática.

- Ranitidina - em caso de sangramento digestivo.

\section{SínDROME DE COMPRESSÃO MEDULAR}

Q uadro com início de dor, seguido de alteração sensorial, fraqueza muscular e, evolutivamente, disfunção esfincteriana.

\section{Conduta:}

- Controlar a dor;

- D exametasona 24mg IV em dose de ataque, seguida de $18 \mathrm{mg} /$ dia por 3 semanas;

- Rever protocolo de radioterapia;

- Cirurgia para descompressão (corporectomia), em cuidados paliativos, é reservada a pacientes com compressão medular sem diagnóstico de câncer; tumor primário controlado; metástase de vértebra sem paraplégica e PS até 2 .

\section{TOSSE E SECREÇÕES NA CRIANÇA}

Tosse: 0 tratamento da tosse cuja causa não pode ser combatida é controverso e baseia-se em experiências com adultos.
Conduta:

- Codeína - 1 - 1,5mg/Kg/24h dividido em $4 / 4$ ou $6 / 6$ horas.

D ose antitussígena.

- N ebulização com broncodilatadores:

Fenoterol - 1 gota/3K g.

- Corticosteróides:

Prednisona - $1 \mathrm{mg} / \mathrm{Kg}$ dividido em 12/12 horas VO.

Secreções:

Acometimento neurológico grave implica em dificuldade de deglutir saliva. I sso leva a desconforto por acúmulo de secreções salivares. M edicações anticolinérgicas podem ser usadas.

- H ioscina - 0,06125 a 0,250mg Vo de 4/4 horas; ou

- Atropina - 0,01mg/Kg/dose SC ou VO.

\section{NOTA FINAL}

Para o IN CA, qualquer conduta aplicada em suas unidades hospitalares que se encontre fora das aqui especificadas é considerada experimental ou irregular.

\section{SIGLAS ADOTADAS}
$A B D$ - água bidestilada
AVE - acidente vascular encefálico
AIN H - anti-inflamatório não hormonal
CNE - cateter naso-entérico
CNG - cateter naso-gástrico
CP - cabeça e pescoço
dl - decilitro
g - gramo
gt- gota
GTO - gastrostomia
$\mathrm{H}$ - hora
$\mathrm{H} \mathrm{b}$ - hemoglobina
H V - hidratação venosa
IECA - inibidor da enzima de conversão da angiotensina
IM - intramuscular
IV - intra-venoso
$\mathrm{Kg}$ - kilograma
mg - miligrama
$\mathrm{ml}$ - mililitro
M M II - membros inferiores
M M SS - membros superiores
M RSA - S. aureus multi-resistente 
PS - "performance status" (capacidade funcional)

RXT - radioterapia

SC - subcutâneo

SF - soro fisiológico

SG - soro glicosado

SM T - sulfametoxazol trimetropim

SM Z - sulfametoxazol

TGI - trato gastro-intestinal

TGU - trato genito-urinário

TRO - terapia de reidratação oral

UI - unidade internacional

VO - via oral

VT - via tópica

\section{ANEXO 1}

\section{RADIOTERAPIA PALIATIVA}

Priorizar pacientes com PS até 3.

M etástase óssea: $80 \%$ dos pacientes respondem em 1 a 2 semanas, independente da radio sensibilidade. Também melhora a dor da fratura patológica.

$M$ aior benefício nos tumores de mama, próstata, tireóide e pulmão.

Toxicidade varia com o sítio e extensão irradiada. G eralmente com duração curta e auto - limitada (se estômago e fígado no campo - náusea evômitos; se intestino delgado - cólica e diarréia).

C aso necessário radiação do hemicorpo, usar pré tratamento: hidrocortisona $100 \mathrm{mg}+$ metroclopramida 10 a $20 \mathrm{mg}$ + hidratação.

M etástase cerebral: alívio da cefaléia em $70 \%$ dos casos. Confusão, déficit motor e sensitivo respondem em $>50 \%$ casos. Após radiação, desmamar corticoterapia.

O bstrução brônquica: tosse e hemoptise - casos persistentes ou que piorem a despeito do tratamento conservador.

D ispnéia: responde em $90 \%$ dos casos.

Compressão de medula: sem instabilidade da coluna. N ecessário diagnóstico e conduta nas primeiras 72 horas do início dos sintomas.

Síndrome de veia cava superior: após tratamento conservador. $M$ anter corticóide após RXT.

Tumores exofíticos: visa controle do crescimento tumoral, do exsudato e do sangramento.

Hemorragia: casos de hemoptise, metrorragia, hematúria, sangramento retal e sangramento de estoma.

\section{ANEXO 2}

\section{ANTIBIOTICOTERAPIA}

Estas são sugestões de antibioticoterapia quando para início empírico, nos casos em que a evidencia da literatura tradicional já denota o germe provável. N outro sim, é preferencial haver coleta de culturas para tratamento específico e discernimento do valor quantitativo de colônias bacterianas.

A avaliação da eficácia do tratamento proposto advém da resposta clínica e laboratorial específica.

Alertamos para as correções que se façam necessárias com relação a função renal ou hepática

Erros passíveis de ocorrerem:

- seleção inapropriada da droga ou via de administração;

- drenagem incorreta de abscesso;

- superinfecção;

- resistência à droga estabelecida;

- associação não identificada de 2 ou mais agentes etiológicos;

- imunodeficiência do paciente;

- causas não infecciosas.

Em alguns casos, a infecção é parte natural do processo de morte e o uso de antibióticos não altera o prognóstico.

0 uso de antibióticos está associada a reações adversas sérias. Com isso, a decisão do uso deve ser baseada na evidência da presença de uma infecção tratável.

- Bacteriúria é comum em pacientes com câncer avançado e universal em pacientes cateterizados, com isso devem ser tratados se houver sintomas de infecção do trato urinário (febre e disúria).

- Grande desvio para esquerda no diferencial de células brancas só nos autoriza a iniciar antibioticoterapia se o paciente estiver sintomático efor se beneficiar do procedimento. 


\section{Pneumonia:}

\begin{tabular}{|c|c|}
\hline comunitária & cefalexina $(0,5$ a $1 \mathrm{~g} 6-8 \mathrm{~h})$ ou cefalotina $(1$ a $2 \mathrm{~g} 6 / 6 \mathrm{~h})$ \\
\hline hospitalizado & ceftriaxona (1 a $2 \mathrm{~g} /$ dia IM ou IV) \\
\hline paciente neutropênico & $\begin{array}{l}\text { amicacina ( } 15 \mathrm{mg} / \mathrm{kg} / \text { dia) + ceftazidime ( } 1 \text { a } 2 \mathrm{~g} 8 \text { - } \\
12 \mathrm{~h} \text { ) com infiltrado localizado (associar vancomicina - } \\
30 \text { a } 50 \mathrm{mg} / \mathrm{kg} / \text { dia em } 2 \text { doses IV em } 250 \mathrm{ml} \mathrm{SG} 5 \% \\
\text { ou SF } 0,9 \% / 125 \text { a } 500 \mathrm{mg} \\
6 / 6 \mathrm{~h} \text { VO - se história de MRSA) considerar fungos }\end{array}$ \\
\hline $\begin{array}{l}\text { paciente neutropênico com } \\
\text { infiltrado bilateral difuso }\end{array}$ & $\begin{array}{l}\text { associar SMT (SMZ }=100 \mathrm{mg} / \mathrm{kg} / \mathrm{dia} \text { IV } 4 / 4 \mathrm{~h}) \\
\text { considerar tuberculose }\end{array}$ \\
\hline $\begin{array}{l}\text { paciente neutropênico } \\
\text { infiltrado focal ou difuso } \\
\text { tardio }\end{array}$ & considerar fungo; \\
\hline broncoaspiração & $\begin{array}{l}\text { ciprofloxacina (250 a } 750 \mathrm{mg} 12 / 12 \mathrm{~h} \text { VO - } 200 \text { a } \\
400 \mathrm{mg} 8-12 \mathrm{~h} \mathrm{IV})+ \text { ampicilina }(0,5 \text { a } 1 \mathrm{~g} \text { a cada } 6 \text { - } \\
8 \mathrm{~h}) \text {. }\end{array}$ \\
\hline
\end{tabular}

\section{Infecç̃̃o urinária:}

\begin{tabular}{|l|l|}
\hline comunitária & SMT (2 cp 12-12h VO) \\
\hline hospitalizado & ampicilina + amicacina \\
\hline
\end{tabular}

\section{Ulcera de decúbito:}

\begin{tabular}{|l|l|}
\hline $12 \mathrm{~h}$ & $\begin{array}{l}\text { ampicilina + amicacina +metronidazol (250 a 750mg } \\
8-12 \mathrm{~h} \text { VO ou IV) }\end{array}$ \\
\hline
\end{tabular}

\section{Colangite colecistite:}

ampicilina + amicacina

\section{Diarréia:}

com febre, hemorragia, desidratação

SMT (sem antibiótico prévio) metronidazol (com antibiótico prévio)

\section{Diverticulite:}

\begin{tabular}{|l|l|}
\hline sem perfuração & ceftriaxona + metronidazol \\
Abscesso Periretal & \\
\hline
\end{tabular}

\section{Celulite erisipela:}

\begin{tabular}{|l|l|}
\hline não complicada & cefalotina \\
\hline complicada & ciprofloxacina + metronidazol \\
\hline & pen. Benzatina \\
recorrente com linfedema & $(1,200.000$ a $2,400.000$ UI IM \\
& $2-3$ semanas $)$ \\
\hline
\end{tabular}

\section{Vascular:}

\begin{tabular}{|l|l|}
\hline tromboflebite séptica & oxacilina $(0,5$ a $1 \mathrm{~g}, 4-6 \mathrm{~h})+$ amicacina \\
\hline
\end{tabular}

\section{Ouvido:}

\begin{tabular}{|l|l|}
\hline otite externa & $\begin{array}{l}\text { polimixina B + neomicina + Hidrocortisona (gts 4x } \\
\text { dia) }\end{array}$ \\
\hline otite & ciprofloxacina \\
\hline mastoidite & cefalotina \\
\hline
\end{tabular}


10. Boca:

\begin{tabular}{|l|l|}
\hline celulite & ceftriaxona \\
\hline estomatite herpética & acycovir (100 a 200mg 6/6h VO) \\
\hline
\end{tabular}

\section{Sinusite:}

\section{Candidiase:}

\begin{tabular}{|l|l|}
\hline sistêmica com metástase & fluconazol $(50$ a $800 \mathrm{mg} / \mathrm{d}$ VO ou $\mathrm{VI})$ \\
\hline mucocutâneo & cetoconazol $(200$ a $400 \mathrm{mg} / \mathrm{d} \mathrm{VO})$ \\
\hline oral & fluconazol \\
\hline urinária & fluconazol \\
\hline vaginal & fluconazol + tópico \\
\hline
\end{tabular}

\section{Tumor exsudativo:}

$$
\text { pomada de metronidazol a } 0,8 \%
$$

O bs.:

Tuberculose:

- 2 meses:rifampicina $600 \mathrm{mg} / \mathrm{dia}$; isoniazida $400 \mathrm{mg} / \mathrm{dia}$; pirazinamida $2 \mathrm{~g} / \mathrm{dia}$.

- 4 meses:rifampicina $600 \mathrm{mg} / \mathrm{dia}$;

isoniazida $400 \mathrm{mg} / \mathrm{dia}$.

- se extra-torácica: +6 meses de isoniazida.

\section{ANTIBIOTICOTERAPIA NA CRIANÇA}

\begin{tabular}{|c|c|c|c|}
\hline$\frac{\text { Infecções }}{\text { Infecções específicas }}$ & Sintomas & Tratamento & Observações \\
\hline \multirow[b]{2}{*}{ Candidíase } & $\begin{array}{l}\text { Alteração do paladar, } \\
\text { Dor, inflamação da } \\
\text { mucosa e } \\
\text { sangramento bucal }\end{array}$ & $\begin{array}{l}\text { Nistatina - } \\
200.000-500.000 U \\
\text { em bochecho, } \\
\text { gargarejo e deglutido } \\
4 \times \text { /dia }\end{array}$ & \\
\hline & $\begin{array}{l}\text { A candidíase } \\
\text { eesofageana está } \\
\text { associada à esofagite, } \\
\text { dor retroesternal ou } \\
\text { sensação de } \\
\text { obstrução na } \\
\text { deglutição }\end{array}$ & $\begin{array}{l}\text { Cetoconazol - } \\
5 \text { a } 10 \mathrm{mg} / \mathrm{Kg} / \text { dia em } \\
\text { dose única }\end{array}$ & $\begin{array}{l}\text { Observar a } \\
\text { interação } \\
\text { medicamentosa do } \\
\text { cetoconazol e } \\
\text { fluconazol com } \\
\text { cisaprida, pelo risco } \\
\text { de arritmia cardíaca }\end{array}$ \\
\hline Herpes oral & & $\begin{array}{l}\text { Aciclovir - } \\
750 \mathrm{mg} / \mathrm{m} 2 / \text { dia - IV de } \\
8 / 8 \mathrm{~h} \text { ou } 200 \mathrm{mg} / \text { dose } \\
5 x / \text { dia VO }\end{array}$ & \\
\hline $\begin{array}{l}\text { Infecção por } \\
\text { anaeróbio }\end{array}$ & & $\begin{array}{l}\text { Metronidazol - } \\
7,5 \mathrm{mg} / \mathrm{Kg} / \mathrm{dose} \text { de } \\
6 / 6 \mathrm{~h}\end{array}$ & \\
\hline Pneumonia & & $\begin{array}{l}\text { Antibiótico, oxigênio, } \\
\text { broncodilatadores, e } \\
\text { morfina ou sedação } \\
\text { para aliviar a dispnéia }\end{array}$ & $\begin{array}{l}\text { Dependendo da } \\
\text { condição clínica da } \\
\text { criança, prover } \\
\text { apenas tratamento } \\
\text { sintomático }\end{array}$ \\
\hline
\end{tabular}




\section{Profilaxia Antimicrobiana em Cirurgias Oncológicas}

Cirurgia de tumores necrosados ou ulcerados:

A coleta de material para cultura em superfícies abertas ou ulceradas (swab) deve ser precedida de limpeza mecânica utilizandose soro fisiológico. 0 antibiótico a ser utilizado no préoperatório deve ser iniciado de acordo com o antibiograma e mantido em doses elevadas durante 0 ato cirúrgico, afim de controlar a disseminação da infecção durante o manuseio cirúrgico. Q ualquer material, de aspecto purulento ou não, encontrado durante 0 ato operatório deve ser encaminhado para cultura e antibiograma. A manutenção deste antibiótico no pósoperatório deve ser discutido.

\section{Profilaxia Antimicrobiana}

Gastrostomia e transversostomia: cefazolina 2g;

Colostomia terminal e fístula mucosa: cafazolina $2 \mathrm{~g}+$ metronidazol $1 \mathrm{~g}$.

O bs.: a $600 \mathrm{mg}$ pri2gm $600 \mathrm{mg}$ e $400 \mathrm{mg}$ ira dose deve ser feita na indução anestésica,caso a intervenção seja longa (acima de 2 horas) ou existir perda de sangue maior que 1 litro, administrar a 2aㅡ dose intra-operatória ( $1 \mathrm{~g}$ de cefazolina $2 \mathrm{~g}$ ). Se necessário a 3a dose, fazer após 3 horas a 2ª dose.

A associação com metronidazol éindicada quando os patógenos anaeróbios constituírem grande parte da flora residente. A presença de drenos não justifica, normalmente, a manutenção além do período crítico do ato operatório (contaminação grosseiramente estende a profilaxia em 24 horas).

A dose de cafazolina $2 \mathrm{~g}$ para peso menor que $50 \mathrm{~kg}=30 \mathrm{mg} / \mathrm{kg} / \mathrm{lV}$.

- Em casos de alergia a betalactâmicos: vancomicina $1 \mathrm{~g} 1 \mathrm{~g}$ IV $30 \mathrm{mg}$ em $1 \mathrm{~g}$, dose única;

- Em caso decultura de urina positiva recente, considerar o processo cirúrgico como infectado.

\section{BIBLIOGRAFIA}

Baines MJ. Intestinal obstruction. Cancer Surv 1997;21:147-56.

Benitz W, Tatro D. Thepediatric drug handbook. 3rd ed. St. Louis: M osby-Year Book.

Bennett, Plum. Cecil textbook of medicine. 20th ed. Philadelphia: W. B. Saunders; 1996.

Collins J , Bred CB. M anagement of cancer pain in children. In: Pizzo, Poplack. Principlesand practice of pediatric oncology. 3rd ed. Philadel phia: Lippincott-Raven; 1997.

D ickerson, D uke. The 20 essential drugsin palliativecare. Eur J Palliat C are 1999;6(4).

D oyle D, H anks G, M ac D onald N. Textbook of palliative care. 2nd ed. O xford U niversity Press; 1999.

Gibbon, D avid C, Sabiston Jr, Spencer FC. Surgery of the chest. 4th ed. Philadelphia: W. B. Saunders; 1983.

Instituto $\mathrm{N}$ acional de $\mathrm{C}$ âncer (Brasil). Controlede sintomas do câncer avançado em adultos: normase recomendações do I N Ca. Rev Bras Cancerol 2000;46(3):243-56.

Instituto $\mathrm{N}$ acional de $\mathrm{C}$ âncer (Brasil). $\mathrm{N}$ ormas e condutas daCCIH/H Cl/IN CA. 2000. D isponível em: ccih@inca.org.br.

Instituto $\mathrm{N}$ acional deC âncer (Brasil). 0 rientações para prescrição de analgésicos no tratamento do câncer [mimeografado].

International Commitee of M edical J ornal Editors. U niform requirements for manuscripts submitted to biomedical journals. Ann Int M ed 1982;96(Pt 1):766-71.

Kaye P. Pocketbook of symptom control. EPL; 1996.

Komurcu S, N elson KA, Walsh D, D onnelly SM , H omsi J, A bdullah O. Common symptomsin advanced cancer. Semin O ncol 2000;27(1):24-33.

Levetown $M$. Treatment of symptoms other than pain in pediatric palliativecare. In: Portenoy, Bruera. Topics in palliative care: pediatric palliative carethe management of bone. 0 xford U niversity Press; 1998. p. 51.

M uir JC, von Gunten CF. Antisecretory agents in gastrointestinal obstruction. Clin Geriatr M ed 2000;16(2):327-34.

Murad A, Katz A. O ncologia. Rio de Janeiro: Guanabara Koogan;1996.

$\mathrm{N}$ elson, KA. The cancer anorexia-cachexia syndrome. Semin O ncol 2000; 27(1):64-8.

Salvajoli JV, Weltman E. Princípiosderadioterapia. 
1st ed. Rio de Janeiro: G uanabara K oogan; 1996.

Sanford J, G ilbert D, Sande M . G uide to antimicrobial therapy. 1995.

Tierney L, M c PheeS, Papadakis M . M edical diagnosisand treatment. Appleton \& Lange; 1999.

Waller, $\mathrm{C}$ aroline. $\mathrm{H}$ andbook of palliative care in cancer. 2nd ed. Butterworth-heinemann; 2000.

Webb M, M oody LE, M ason LA. Dyspnea asserment and management in hospicepatients with pulmonary disorders. Am J Hosp Palliat Care 2000;17(4):259-64.
Welsh J, Fallon M. H andbook of palliative care. 3rd ed. Blackwell Science; 2000.

Weisman SJ. Pediatric palliativecare: afield in evolution. In: Portenoy, Bruera. Topicsin palliativecare: pediatric palliative care the management of bone. O xford U niversity Press; 1998. p. 3.

W orld $\mathrm{H}$ ealth O rganization Collaborating C enter for Policy and $\mathrm{C}$ ommunications in $\mathrm{C}$ ancer $\mathrm{C}$ are. Pain in children with cancer: $\mathrm{T}$ heW orld $\mathrm{H}$ ealth O rganization-IASP guidelines. Cancer Pain Rellief 1999;12(1). 